\title{
Primary Omental Infarction Presenting As a Parietal Wall Swelling: A Rare Case Report
}

\author{
Authors \\ Dr Samarth Agarwal ${ }^{1}$, Dr Aftab Shaikh², Dr M S Navare ${ }^{3}$, Dr Aman Singh ${ }^{4}$, \\ Dr M B Tayade 5 \\ ${ }^{1}$ Lecturer, ${ }^{2}$ Associate Professor, ${ }^{3}$ Associate Professor, ${ }^{4}$ Senior Resident, ${ }^{5}$ Professor \\ Grant Government Medical College and Sir J J Group of Hospitals, Mumbai \\ Corresponding Author \\ Dr. Samarth Agarwal \\ Lecturer, Dept of General Surgery, Grant Medical College and sir J J group of Hospitals, Mumbai \\ Email: rebellite@gmail.com
}

\begin{abstract}
Primary omental infarction, acute or subacute, may present as acute abdomen or as sub-acute abdominal pain which frequently mimics other surgical emergencies. Primary omental infarction is idiopathic ${ }^{[1]}$ in contrast to secondary which is associated with other intra abdominal pathologies. We present here a case of primary omental infarction with abscess formation infiltrating into the anterior abdominal wall muscle layers, presenting as abdominal pain with parietal wall swelling (in contrast to intra abdominal lump which is the common presentation) eventually managed with surgical intervention.

Keywords: omental infarction; omental abscess; parietal wall swelling; acute abdomen
\end{abstract}

\section{INTRODUCTION}

Omental infarction is a rare but important cause of acute or subacute abdomen. Omental infarction has been reported in the literature over 100 years ago, first reported by Bush in $1896^{[2,3]}$. It has been reported at a rate of $0.1 \%$ of all laparotomies performed for acute or subacute abdomen ${ }^{[4]}$ with an incidence of $0.0016-0.37 \%{ }^{[5]}$. Clinically, majority of patients present with acute or subacute abdominal pain as with our patient, which may be to the left or right side of the midline based on the side of omental involvement. Pain may mimic acute appendicitis $(66 \%)$ or cholecystitis ${ }^{[6]}$. In female patients it may mimic gynecologic problems.

The physical findings are variable but tenderness is usually in the right side of the abdomen, predominantly at the right lower quadrant as seen with our patient. Physical examination usually elicits localized tenderness with or without a palpable intra abdominal "mass" indicating abscess formation. Our patient though had palpable mass, but clinically was appearing to arise from abdominal wall as a result of abdominal wall infiltration, which is a unique finding in such cases. 


\section{JMSCR Vol.||03||Issue ||08||Page 7267-7270||August}

\section{CASE REPORT}

A 40 year-old male patient presented with pain in the right lower quadrant of abdomen since 2-3 months which was dull aching, vague, non radiating, non migrating, partially relieved by medications. This was not associated with any history of vomiting or fever. It was not associated with any bowel or urinary complaints.

On examination, he was hemodynamically stable, afebrile. Per abdomen examination showed no tenderness or guarding or rigidity, but an ill defined lump was palpable in lower right umbilical region of approximately $(4 \times 4) \mathrm{cm}$ size with Carnett's test suggestive of intra parietal swelling, with smooth surface and firm consistency.

His abdominal CT (fig. 1,2) was suggestive of confluent areas of fat stranding in right iliac fossa indicating omental infarction. No other intra abdominal pathology detected.

Patient was initially given a trial of conservative management but the pain did not settle down. Hence he was operated electively with diagnostic laparoscopy done which confirmed right omental infarction with abscess formation infiltrating into the abdominal wall muscle layers and adherent to it (fig. 3). Hence a midline laparotomy incision was taken \& partial omentectomy was performed with removal of the diseased omentum and abscess. The cavity extending into abdominal wall was scooped off thoroughly with betadine washes. On histopathology (fig. 4), omental infarction was confirmed with extensive areas of necrosis, ill formed granulomas, with dense mixed inflammatory infiltrate composed of polymorphs and lymphocytes. No evidence of caseous necrosis or fungi or atypia or malignancy found. A lymph node was also isolated showing reactive sinus histiocytosis.

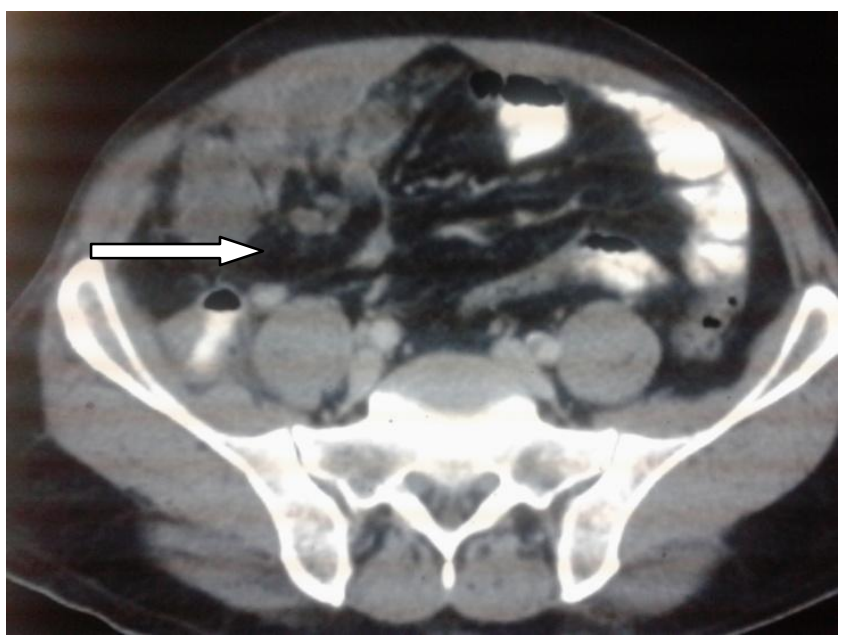

Fig. 1: Axial CT plate showing omental infarction with fat stranding extending into parietal wall

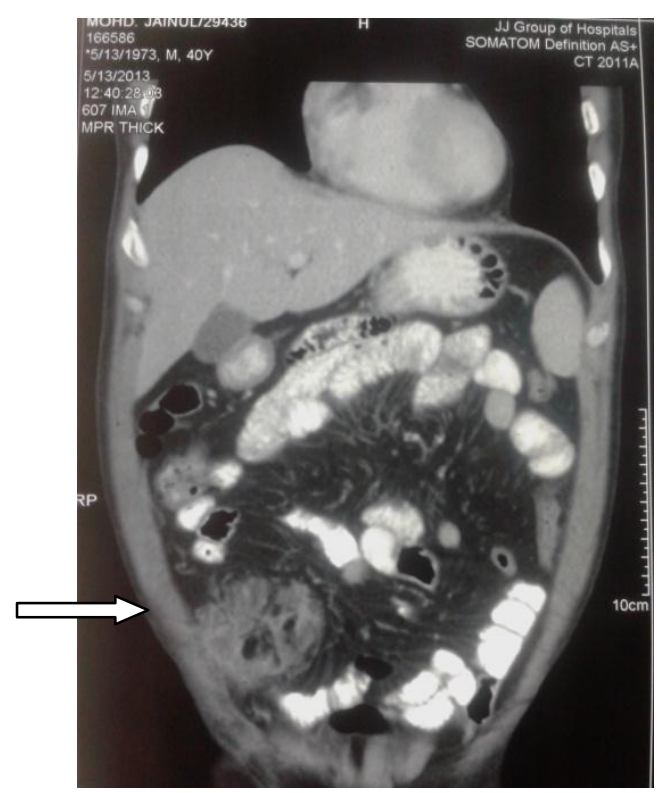

Fig. 2: Coronal CT plate showing the omental infarction with abscess formation

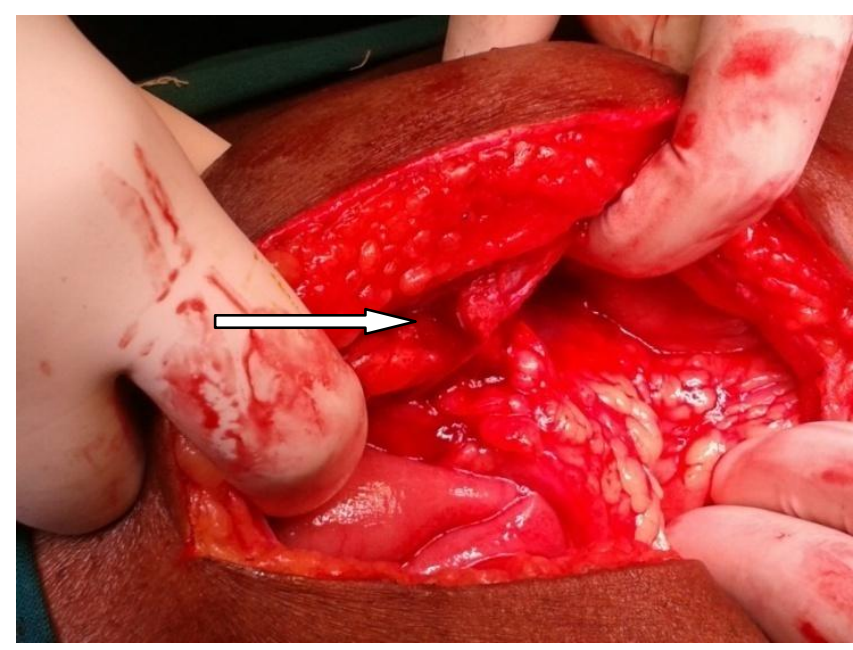

Fig. 3: Intra operative photograph of omental abscess extending into parietal wall 


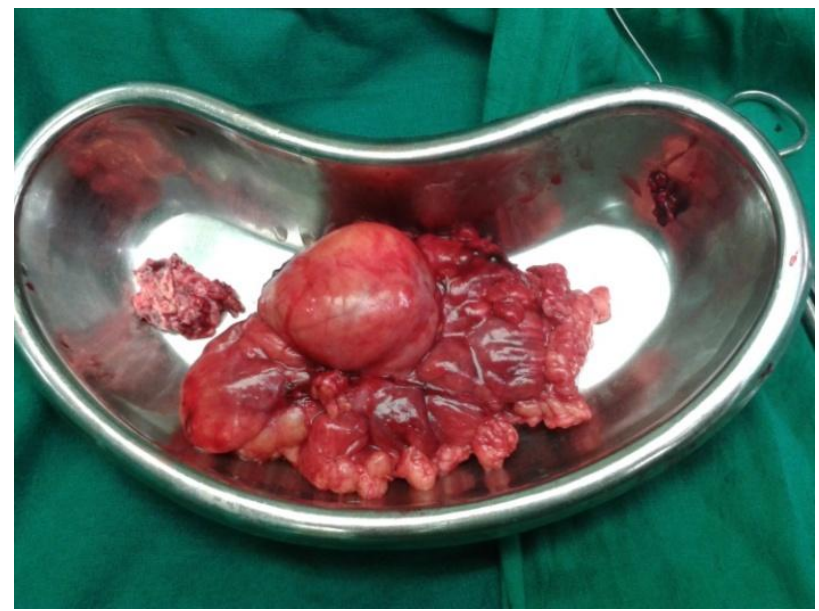

Fig, 4: Post operative photograph of resected omentum with abscess

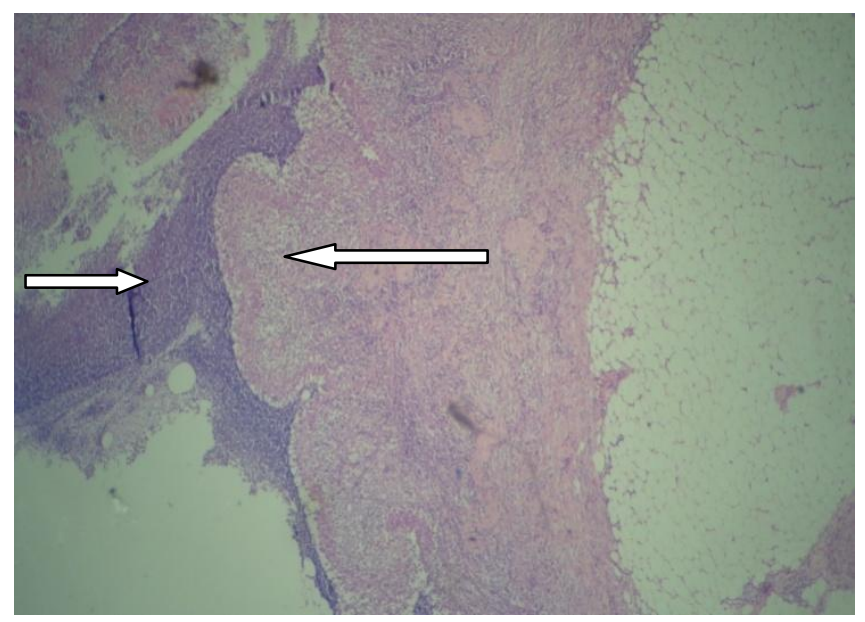

Fig. 5: Histopathology slide showing granuloma (bigger arrow) and inflammatory infiltrate (smaller arrow) s/o abscess formation

\section{DISCUSSION}

Omental infarction is classified as primary when there is no identifiable etiology, or secondary when it is associated with other intra-abdominal pathologies such as adhesions, malignancy, hernias, cysts or other inflammatory diseases. The exact pathogenesis of this condition is unknown. It has been postulated that congenitally anomalous fragile blood supply to the right greater omentum makes this region prone to infarction ${ }^{[6]}$. Others have suggested a different embryonic origin of right greater omentum with more fragile blood vessels which are more susceptible to elongation and secondary occlusions. This explains the high incidence $(90 \%)$ of this disease in the right side of greater omentum ${ }^{[7]}$. Other predisposing factors include obesity or trauma, overeating, hypercoagulability, coughing or a sudden change in position $\left.{ }^{[6,8}, 9,10,11\right]$. Temperature is usually normal or slightly raised associated with leucocytosis. Therefore omental infarction is extremely difficult to diagnose clinically and radiological investigations are required to confirm the diagnosis. Ultrasonography findings include a hyperechoic, noncompressible, ovoid mass. Typical Computed Tomography findings include a streaking or "whirling" pattern of inflammatory fatty tissue with a fluid cavity ${ }^{[7]}$.

Conservative management may be tried for patients who are clinically stable ${ }^{[12,13]}$. But in cases of inconclusive radiological findings, or non resolution with medical management, or unstable patients, or those with complications such as omental abscess, bowel obstruction or adhesion formation, laparoscopy is often necessary to establish a definitive diagnosis and management. Our patient was given conservative trial for about 1 month but due to abscess formation and nonresolution of disease with conservative management was the reason for operative management.

Surgical management usually involves omentectomy, laparoscopic approach being preferred which allows visualization of other intra-abdominal organs for associated pathology. Our patient was initially operated with laparoscopy but due to the presence of parietal wall infiltration the procedure was converted to laparotomy with partial omentectomy.

\section{CONCLUSION}

Omental infarction should be kept in mind while dealing with acute/subacute abdominal pain. The exact aetio-pathogenesis of primary omental infarction is still unknown. Increased awareness of this condition, combined with the use of Ultrasonography or Computed Tomography has increased the diagnostic accuracy and hence prompt effective management of these cases. Also a parietal wall ill defined swelling in the setting of omental infarction can be due to the abscess 
cavity infiltrating into abdominal wall should also be kept in mind while managing such cases.

\section{REFERENCES}

1. Varjavandi V., Lessin M., Kooros K.,Fusunyan R., McCauley R.,Gilchrist B.: Omental infarction: riskfactors in children. J Pediatr Surg,2003, 38:233-235.

2. P. Bush, A case of haemorrhage into the greater omentum, The Lancet, 1896;147(3779):286.

3. G. Eittel, Rare omental torsion, NY Med Rec, 1899;55:715-6.

4. F.C. Abente, P. Ferraina, J.M. Lardies, A. Napolitano, L. Sarotto, Primary segmental infarction of the greater omentum: a rare cause of RLQ syndrome: laparoscopic resection, Surg Laparosc Endosc Percutan Tech [Case Reports], 2001 Feb;11(1):60-2.

5. J. Khersonsky, E. Itenberg, J. Mariadason, M. Wallack, Modern management of omental torsion and omental infarction: a surgeon's perspective, Journal of Surgical Education [Case Reports], 2010 JanFeb;67(1):44-7.

6. Sanchez J, Rosado R, Ramirez D, Medina P, Mezquita S, Gallardo A: Torsion of the greater omentum: treatment by laparoscopy.Surg Laparosc Endosc Percutan Tech 2002, 12:443-445

7. E.K. Abdennasser, D. Abdellatif, B. Driss, A. Mehci, B. Mohamed, C. Souad, Omental torsion and infarction: CT appearance. Internal Medicine. [Case Reports], 2008;47(1):73-4.

8. S. Khanna, N. Patle, P.K. Sasmal, O. Tantia, Omental torsion and infarction: a diagnostic dilemma and its laparoscopic management, Journal of Laparoendoscopic \& Advanced Surgical Techniques, 2010 Apr;Part A. 20(3):225-9.

9. E. Chatzigianni, A.J. Karayiannakis, Primary torsion of the greater omentum:
Report of a case, Surg Today, 2002;32:913-5.

10. J.B. Puylaert, Right-sided segmental infarction of the omentum: clinical, US, and CT findings, October 1992 Radiology, 185, 169-172.

11. C.L. Fernandez-Rey, Primary omental infarction as cause of non-surgical acute abdomen: imaging diagnosis, Revista Espanola de Enfermedades Digestivas [Case Reports], 2010 Jul 2010;102(8):4989.

12. B. Coulier, Contribution of US and CT for diagnosis of intraperitoneal focal fat infarction (IFFI): a pictorial review, JbrBtr: Organe de la Societe Royale Belge de Radiologie. [Review], 2010 JulAug;93(4):171-85.

13. J.A. Albasini, M.F. Arenas, V.S. Aledo, E.G. Baena, M.C. Arenas , J.A. Jimenez, M.J. Perello, B.F. Pastor, [Omental torsion: imaging techniques can prevent unnecessary surgical interventions], Gastroenterologia y Hepatologia [English Abstract Review], 2002 Oct;25(8):493-6. 